\title{
Effectiveness of nursing care in Epilepsy
}

Maryam Izadi Laybidi ${ }^{1^{*}}$ and Miranda Mehdinejad ${ }^{2}$

${ }^{1}$ Department of Neurology, Esfahan Neurosciences Research Center, School of Medicine, Isfahan University of Medical Sciences, Isfahan, Iran

${ }^{2}$ Department of Medicine, Isfahan University of Medical Sciences, Isfahan, Iran

*Corresponding author: Laybidi MI, Department of Neurology, Esfahan Neurosciences Research Center, School of Medicine, Isfahan University of Medical Sciences, Isfahan, Iran, Tel: + 989133002820; E-mail: maryam.izadi91@yahoo.com

Received date: April 05, 2018; Accepted date: May 17, 2018; Published date: May 24, 2018

Copyright: $\odot 2018$ Laybidi Ml, et al. This is an open-access article distributed under the terms of the Creative Commons Attribution License, which permits unrestricted use, distribution, and reproduction in any medium, provided the original author and source are credited.

\begin{abstract}
The purpose of this study was to investigate the effectiveness of nursing care in epilepsy. In this experimental study, 120 nurses from hospitals in Isfahan were randomly divided into control and experimental groups (60 each). The data collection tool was a questionnaire based on nursing care in epilepsy. The case group received an educational program for one month and 3 months after the educational intervention, both groups completed the questionnaire and the data was analyzed. The findings of the study indicated that there was no significant difference between the two groups in terms of professional behavior, communication, personal approach, empathy and respect before the educational intervention, while after the intervention, the mentioned factors significantly increased in the experimental group, in comparison to the control group $(p=0.001)$. Based on this study, the designed nursing care education program is effective in promoting nurses' professional behaviors, communication, personal approach, empathy and respect. In addition, educational control, monitoring and follow up are recommended in the implementation of these programs.
\end{abstract}

Keywords: Nursing care; Epilepsy; Hospital

\section{Introduction}

In neurology, epilepsy is referred to a situation in which a person has frequent episodes of seizure without any specific stimuli such as low blood sugar, fever, calcium deficiency or the like. In children and young people, epilepsy is often attributed to birth defects, congenital anomalies, or genetic disorders affecting the brain [1]. The most cause of epilepsy is cryptogenic (Idiopathic) [2]. In middle-aged and elderly people, strokes, tumors, and cerebrovascular disease are the most common causes of epilepsy. Epilepsy is one of the most common and important neurological diseases, of which approximately 60 million people in the world (about 1\%) are involved with this issue and 2.5 million new cases are added each year. For $25-30 \%$ of patients, there is no standard drug combination (medicine or surgery) to control their seizure. These patients suffer from treatment-resistant or drugresistant epilepsy [3].

Epilepsy is the most common neurological disorder in childhood. Nearly half of the cases of epilepsy occur in childhood. Epileptic children and their parents face many social and psychological problems. Problems of socialization, anxiety, cognitive impairment and behavioral disorders were observed in 39.8\%, 45.8\%, 49.4\% and $42.2 \%$ of children with epilepsy, respectively. According to the official website of epilepsy, about 60 million people in the world suffer from epilepsy, where an average of between 125,000 and 150,000 are added to this infection, each year, from among which about $30 \%$ are children. One in 10 people has a seizure at least once in a lifetime. The rate of people with epilepsy in Iran is about 1 million. Up to now, therapeutic approaches based on nursing care have been proposed for epilepsy, which are effective in most cases and can certainty be used to treat epilepsy [4].
One of the key occupations in healthcare settings is nursing and nurses make more than $70 \%$ of the health care team [5]. In care, as an important part of nursing, it is widely accepted by nurses and nursing researchers and is synonymous with nursing practices. This concept is a typical example of feeling, thought and action that provides physical and mental comfort [6].

Caring is at the center of nursing practices and in emphasizing the importance of nurse care role since 1990, Henchilof considers caring from the patient as the base of nursing and believes that, regardless of any changes that are made in the professional role of the nurse, caring from the patient as the basis of this profession. Caring along with respect and respecting for the life of a person is an integral part of the nursing role and responsibility. In this role, the nurse identifies the total health care needs of the patient, including methods for emotional, spiritual and social welfare rehabilitation. In fact, caring helps both the patient and the family to compile goals and achieve them at minimum cost, time and energy. Also, due to the emphasis on resource management, cost control, the effectiveness of patient care, promotion of quality and accountability, good care of the patient is necessary [7].

Nursing care has two aspects of emotions and activities, the first dimension is related to the attention to the patient as a person and paying attention to what happens to him. In other words, the emotional dimension of caring for dignity, the position and independence of the other person is respected. The dimension of activities is aimed at helping and serving others through nurse-patient communication. In fact, this dimension of care is about diagnosing and meeting the patient's needs. Canawaktiquel et al. obtained the following key themes in defining the quality of nursing care:

- Achieving the physical needs of patients

- Providing psychosocial support for patients

- Ensuring the attention to the spiritual needs of patients

- Satisfaction of patients from the cares 
- Accountability of the nursing care for patient needs

- Ensuring about the provision of comprehensive care for the patient

The quality of nursing care is the response of nursing to physical, psychological, emotional, social and spiritual needs of patients, so that they return to their healthy and natural lives and the satisfaction of patients and nurses is attracted. In a qualitative study, Barhans and Aligood (2010) expressed the qualitative nursing from the nurse's perspective in terms of meeting human needs through attention, empathy, respectful interactions with the patient, along with the sense of responsibility, basic and integral support of the patient [8]. Also epilepsy nurse is a professional care for management and evaluation of patients with complex epilepsy [9].

Despite the high profile of physicians as the founders of self-care education in the world and Iran, numerous articles today have indicated that nurses have a unique position in providing care at the time of disaster to improve the quality of life of affected people and improve their quality of life. An important part of self-care education in disasters is done by nurses. One of the educational interventions conducted by nurses in the world and Iran can be referred to individual education and group training [10]. Considering the role of nursing care in improving the adaptability of epilepsy patients, this study attempts to address the effectiveness of nursing care in epilepsy nursing.

\section{Materials and Methods}

The present study is a quasi-experimental study conducted on 120 epilepsy nurses of hospitals in Isfahan. This study was done on the hospitalized patients with complex uncontrolled Epilepsy and the patients were under treatment with antiepileptic drugs. The sample size was obtained with a confidence level of $95 \%$ as 120 using the sample volume formula to compare the mean of the two groups, and they were alternatively assigned to intervention and control groups in a random way. The data collection tool was a questionnaire consisting of two sections: demographic characteristics and nursing care behaviors of epilepsy nursing including professional behavior (6 items), communication (5 items), individual approach (6 items), empathy (5 items) and respect (5 items). To measure the dimensions of the epilepsy nursing, a 5-point Likert scale was used. Scoring of the questionnaire was such that in the sensitivity, severity, benefits, perceived barriers and self-efficacy of the domain, the score of each question varied from 1 to 5 , so that the answer completely disagree was scored as 1 , disagree as 2, I have no idea as 3 , agree as 4 and completely agree as 5. In sum, the total score of each of these sections (professional behavior, communication, individual approach, empathy, and respect) was calculated based on 100 points.

The validity of the data collection tool has been measured through content validity and through investigating the extensive literature review. The reliability of the research tool through calculating Cronbach's alpha was confirmed to be 0.87 . In this section, the reliability of the professional behavior questionnaire, communication, individual approach and empathy were confirmed to be $0.91,0.84,0.85$ and 0.88 , respectively.

Before conducting the intervention, a pre-test was completed for both groups of participants in the study. The nursing care program was designed and developed after collecting and analyzing the data of the questionnaire. The case group was then subjected to a researcher intervention that is the nursing care program, to be used to improve nursing care in epilepsy patients based on this model. The educational program was implemented using lecture methods along with questions and answers, presentation of pamphlets and booklets in 5 sessions. The lecture method was selected because of saving time and resources, providing a lot of theoretical content in a meeting, and creating a sense of safety and usefulness in the learners. The question and answer method was used more in order to participate in the learning process. One month after the implementation of the training program, the data related to the professional behavior, communication, individual approach, empathy, respect and performance of research units were again collected through the same questionnaire. After data extraction, the data was analyzed by SPSS-23. So that, in order to compare the mean scores of professional behavior, communication, individual approach, empathy and respect in each group, the paired t-test and for Comparison of mean score of professional behavior, communication, individual approach, empathy and respect of these two groups, the independent t-test were used.

\section{Findings}

In this research, 120 nurses of hospitals in Isfahan were enrolled in the study and completed the questionnaires in two stages $(100 \%$ response rate). Their mean age was 40.41 years with a standard deviation of 1.35 and a mean age range of 25 to 50 years. At the beginning of the study, the two groups were similar in terms of demographic characteristics.

Findings of the demographic variables of the research are included in Table 1 . The findings indicate that $65.8 \%$ of respondents are women and $34.2 \%$ are men. Regarding the frequency distribution of respondents according to the age variable, the findings indicate that $12.5 \%$ of respondents aged $20-25,22.5 \%$ aged between 26 and 30 , $31.6 \%$ aged 31 to $35,18.3 \%$ aged 36 to 40 and $15 \%$ aged older than 41 .

\begin{tabular}{|c|c|c|}
\hline Varıables & Frequency & Percentage \\
\hline \multicolumn{3}{|l|}{ Gender } \\
\hline Female & 79 & 65.8 \\
\hline Male & 41 & 34.2 \\
\hline \multicolumn{3}{|l|}{ Age } \\
\hline 20 to 25 & 15 & 12.5 \\
\hline 26 to 30 & 27 & 22.5 \\
\hline 31 to 35 & 38 & 31.6 \\
\hline 36 to 40 & 22 & 18.3 \\
\hline 41 and higher & 18 & 15 \\
\hline
\end{tabular}

Table 1: Demographic findings of the study.

The descriptive indexes of research variables in pre-test and posttest are reported by groups in the table below. According to the Kolmogorov-Smirnov table (Table 2), it is not significant for all variables. Therefore, the distribution of these variables in groups is normal and parametric tests can be used.

The results of Table 3 below indicate that before the intervention, the two groups had no significant difference and were similar in all professional behavior constructs $(\mathrm{p}=0.786)$, communication $(\mathrm{p}=0.491)$, individual approach $(\mathrm{p}=0.135)$, empathy $(\mathrm{p}=0.640)$ and respect $(\mathrm{p}=0.546)$. 
Page 3 of 4

\begin{tabular}{|c|c|c|c|c|c|c|}
\hline Variable & Status & Group & Mean & SD & K-S Z & $\mathbf{P}$ \\
\hline \multirow{4}{*}{$\begin{array}{l}\text { Professional } \\
\text { behavior }\end{array}$} & \multirow{2}{*}{ Pre-test } & Experimental & 10.32 & 1.93 & 0.458 & 0.345 \\
\hline & & Control & 10.11 & 1.84 & 0.365 & 0.547 \\
\hline & \multirow{2}{*}{ Post-test } & Experimental & 13.21 & 1.33 & 0.645 & 0.854 \\
\hline & & Control & 10.32 & 1.85 & 0.536 & 0.658 \\
\hline \multirow{4}{*}{ Communication } & \multirow{2}{*}{ Pre-test } & Experimental & 14.8 & 4.63 & 0.911 & 0.378 \\
\hline & & Control & 13.2 & 1.69 & 0.731 & 0.66 \\
\hline & \multirow{2}{*}{ Post-test } & Experimental & 21.33 & 2.32 & 0.567 & 0.905 \\
\hline & & Control & 13.07 & 2.67 & 0.453 & 0.987 \\
\hline \multirow{4}{*}{$\begin{array}{l}\text { Personal } \\
\text { approach }\end{array}$} & \multirow{2}{*}{ Pre-test } & Experimental & 18.33 & 5 & 0.42 & 0.995 \\
\hline & & Control & 17.27 & 3.63 & 0.759 & 0.612 \\
\hline & \multirow{2}{*}{ Post-test } & Experimental & 21.87 & 2.5 & 0.986 & 0.285 \\
\hline & & Control & 16.47 & 2.5 & 0.727 & 0.666 \\
\hline \multirow{4}{*}{ Empathy } & \multirow{2}{*}{ Pre-test } & Experimental & 14.67 & 3.2 & 0.743 & 0.639 \\
\hline & & Control & 13.4 & 2.56 & 0.692 & 0.725 \\
\hline & \multirow{2}{*}{ Post-test } & Experimental & 20.27 & 2.15 & 0.713 & 0.69 \\
\hline & & Control & 11.8 & 3.38 & 1.007 & 0.262 \\
\hline \multirow{4}{*}{ Respect } & \multirow{2}{*}{ Pre-test } & Experimental & 28.6 & 8.68 & 0.458 & 0.985 \\
\hline & & Control & 29 & 8.07 & 0.489 & 0.971 \\
\hline & \multirow{2}{*}{ Post-test } & Experimental & 42.6 & 3.27 & 0.508 & 0.958 \\
\hline & & Control & 31.27 & 8.07 & 0.734 & 0.654 \\
\hline
\end{tabular}

The results of Table 4 indicated that two months after the intervention, there was a significant difference between the two groups in terms of all the variables of professional behavior $(p=0.001)$, communication $(\mathrm{p}=0.001)$, individual approach $(\mathrm{p}=0.001)$, empathy $(\mathrm{p}=0.001)$ And respect $(\mathrm{p}=0.001)$.

There was no significant difference in the mean scores of variables of professional behavior, communication, personal approach, empathy, and respect, before the educational intervention between the intervention and control groups. However, after the educational intervention, a significant difference was observed between the intervention and control groups in all the variables mentioned. Since the upper and lower limits are both positive in both of these variables, it can be said that the mean scores of professional behavior, communication, individual approach, empathy, and respect of the intervention group are greater than the control group.

\begin{tabular}{|c|c|c|c|c|c|}
\hline Variable & Status & Group & Mean & SD & $\mathbf{P}$ \\
\hline \multirow{2}{*}{$\begin{array}{l}\text { Professional } \\
\text { behavior }\end{array}$} & \multirow[t]{2}{*}{ Post-test } & Experimental & 13.21 & 1.33 & \multirow[t]{2}{*}{0.001} \\
\hline & & Control & 10.32 & 1.85 & \\
\hline \multirow[t]{2}{*}{ Communication } & \multirow[t]{2}{*}{ Post-test } & Experimental & 21.33 & 2.32 & \multirow[t]{2}{*}{0.001} \\
\hline & & Control & 13.07 & 2.76 & \\
\hline \multirow[t]{2}{*}{ Individual approach } & \multirow[t]{2}{*}{ Post-test } & Experimental & 21.87 & 2.50 & \multirow[t]{2}{*}{0.001} \\
\hline & & Control & 16.47 & 2.50 & \\
\hline \multirow[t]{2}{*}{ Empathy } & \multirow[t]{2}{*}{ Post-test } & Experimental & 20.27 & 2.15 & \multirow[t]{2}{*}{0.001} \\
\hline & & Control & 11.80 & 3.38 & \\
\hline \multirow[t]{2}{*}{ Respect } & \multirow[t]{2}{*}{ Post-test } & Experimental & 42.60 & 3.37 & \multirow[t]{2}{*}{0.001} \\
\hline & & Control & 31.27 & 8.07 & \\
\hline
\end{tabular}

Table 2: Descriptive indexes of research variables divided by control and experiment groups $(\mathrm{n}=120)$.

\begin{tabular}{|c|c|c|c|c|c|}
\hline Variable & Status & Group & Mean & SD & $\mathbf{P}$ \\
\hline \multirow{2}{*}{$\begin{array}{l}\text { Professional } \\
\text { behavior }\end{array}$} & \multirow[t]{2}{*}{ Pre-test } & Experimental & 10.32 & 1.93 & \multirow[t]{2}{*}{0.786} \\
\hline & & Control & 10.11 & 1.84 & \\
\hline \multirow[t]{2}{*}{ Communication } & \multirow[t]{2}{*}{ Pre-test } & Experimental & 14.80 & 4.63 & \multirow[t]{2}{*}{0.491} \\
\hline & & Control & 13.20 & 1.69 & \\
\hline \multirow[t]{2}{*}{ Individual approach } & \multirow[t]{2}{*}{ Pre-test } & Experimental & 18.33 & 5 & \multirow[t]{2}{*}{0.135} \\
\hline & & Control & 17.27 & 3.63 & \\
\hline \multirow[t]{2}{*}{ Empathy } & \multirow[t]{2}{*}{ Pre-test } & Experimental & 14.67 & 3.20 & \multirow[t]{2}{*}{0.640} \\
\hline & & Control & 13.40 & 2.56 & \\
\hline \multirow[t]{2}{*}{ Respect } & \multirow[t]{2}{*}{ Pre-test } & Experimental & 28.60 & 8.68 & \multirow[t]{2}{*}{0.260} \\
\hline & & Control & 29 & 8.07 & \\
\hline
\end{tabular}

Table 3: Comparison of epilepsy nursing component scores in both experimental and control groups before the intervention.

Table 4: Comparison of epilepsy nursing component scores in both experimental and control groups after the intervention.

\section{Discussion and Conclusion}

The overall aim of this study was to evaluate the effectiveness of nursing care in nursing staff on epilepsy nurses in Isfahan hospitals. The findings indicated that there was no significant difference between the mean score of professional behavior in intervention and control groups before educational intervention. Whereas, after the intervention, the mentioned factors significantly increased in the experimental group compared to the control group, but no significant difference was observed in the control group in the mean score of people regarding the professional behavior.

The findings of this study indicated that the implementation of nursing care education program has been effective in improving nursing behaviors of the research units. These findings are consistent with the findings of the study conducted by DeVries-Rizzo et al., Zarowitz et al., Lake et al., Vahedi et al., Holland et al. $[1,3,4,6,7]$ in the field of epilepsy nursing.

The results of this study indicated the effect of educational intervention on the respect of epilepsy nurses in the experimental group. Tables 3 and 4 indicate that, before the intervention, there was no significant difference between the two groups in this regard, whereas this difference was significant $(\mathrm{p}=0.01)$ after the intervention. 
Similar to the results of this study, the results of studies by Holland et al. [7] also indicated the effect of educational intervention on the respect of epilepsy nurses in the experimental group.

Increasing the mean score of the individual approach of epilepsy nurses suggests that people had higher skills in an individual approach after the intervention. The findings of this study indicated that the mean score of individual approach before training was 18.33 which increased to 21.87 after the intervention.

In the present study, the mean score of empathy before the intervention was 14.67 which increased to 27.21 , after the intervention. In this study, before the intervention, the average score of respect was 28.60 which increased to 42.60 after the intervention. This increase is due to the participation of nurses in training classes on epilepsy nursing. The results of this study indicated that nursing care education for epilepsy nurses increases their caring behaviors and professional behavior, communication, personal approach, empathy and respect, improved after training the nursing care program.

The limitations of this study were included didn't evaluate of patients, lower samples size and didn't use of standard questionnaire for evaluation of nurses.

\section{References}

1. DeVries-Rizzo M (2016) A description of Canadian epilepsy monitoring units: An initial step toward developing nursing practice consensus guidelines. Epilepsy Behav 57: 145-150.
2. Shorvon SD (2011) "The causes of epilepsy: changing concepts of etiology of epilepsy over the past 150 years." Epilepsia 52: 1033-1044.

3. Zarowitz B, Allen C, O'Shea T, Wang Z, Semenchuk M, et al. (2016) Nursing Home Residents with Seizure Disorders/Epilepsy: Prevalence, Characteristics, and Treatment Patterns (P1. 080). Neurology 86: 1-080.

4. Lake ET, de Cordova PB, Barton S, Singh S, Agosto PD, et al. (2017) Missed Nursing Care in Pediatrics. Hospital Pediatrics, hpeds-2016.

5. Sermeus W (2016) Functionality of Triggers for Epilepsy Patients Assessed by Text and Data Mining of Medical and Nursing Records. Nursing Informatics 2016: EHealth for All: Every Level CollaborationFrom Project to Realization 225: 128.

6. Vahedi M, Vanaki Z, Memarian R (2016) The Effect of Quality Assurance Program on Nursing Care in the Outpatient Center on the Satisfaction of Cataract Surgery Patients and Their Families. Tarbiat Modarres University 5: 27-37.

7. Holland C, Edward KL, Giandinoto JA (2017) Nursing and focal dyscognitive seizures: A clinical update when managing risk using advanced nursing skills. J Neurosci Nurs 49: 164-168.

8. Aqebati N (2013) Explaining the Conceptual Framework of Comprehensive Nursing Care and Designing Nursing Curriculum, Specialized Masters, Tarbiat Modarres University, Faculty of Medical Sciences.

9. Hosking P (2003) Prescribing and the epilepsy specialist nurse. SeizureEuropean J Epilepsy 12: 74-76.

10. Shirazi M (2009) The effect of Self-care program on the self-concept of diabetic adolescent girls, Tarbiat Modarres University, Faculty of Medical Sciences. 